\title{
An Attempt for Obtaining the Aerosol Size Distribution
}

\author{
By Hiroshi Kojima and Toshio Sekikawa \\ Faculty of Science, Science University of Tokyo, Tokyo. \\ (Manuscript received 28 September 1972, in revised form 14 August 1973)
}

\begin{abstract}
A method is proposed for the detection of the size distribution of atmospheric aerosols that have a radius from $5 \times 10^{-7}$ to $5 \times 10^{-6} \mathrm{~cm}$.

To make a charge equilibrium of aerosols in which the fraction of charged particles depends on the size of the aerosols, the sample air containing the aerosols was irradiated with $\mathrm{Po}^{210}(\alpha$ ray, approximately $100 \mu \mathrm{Ci}$ ) and the ion mobility distributions were obtained by the ion analyzer.

The relation between the size (electrical mobility) and the charged fraction of the aerosols irradiated with $\mathrm{Po}^{210}$ was measured. From the result it was known that the Boltzmann distribution law was not valid for the small size.

On the basis of this result, the ion mobility distribution was transferred to the size distribution of the particles. This irradiation method was applied to the measurement of diurnal variation in the size distribution in the urban atmosphere.
\end{abstract}

\section{Introduction}

It is important in the studies of air pollution, natural radioactivety and meteorology to obtain the particle size distribution. One of the effective measuring the size distribution may be the ion counting method which can only obtain the ion mobility distribution of charged particles. The method has some advantages. It enables us to measure aerosols of high concentration with high resolving power and to obtain continuous data. Up to the present, many improvements on the measurement method and the apparatus have been proposed. However, few of them deal experimentally with the relation between ion mobility and particle size distribution (Nalan 1949, Whitby 1966).

Hitherto, assuming that the charge distribution on particles in the atmosphere is in equilibrium, the particle size distribution have been obtained from the measurement of the ion mobility distribution (Junge 1955). Whitby adopted the following unique procedure. The aerosols were mixed with negative ions by sonic jet ion generator and electrical mobility was measured by the electrical mobility analyzer. His automatic analyzer would be available for a size range from $0.01 \mu$ to $0.5 \mu$. But it is reported by Flesch (1969) that the particle size separation of the analyzer is not complete and the resolution obtained by the use of polystylene latex aerosols which are initiaily charged bipolar is not high, paricularly for the range of small size.

We adopted the following principle to obtain size distribution over the range from $5 \times 10^{-7}$ to $5 \times 10^{-6} \mathrm{~cm}$ in radius. Since the charge distribution on aerosols in normal urban air is not in charge equilibrium (Flanagen 1961, Sekikawa 1969), the airflow containing aerosol was irradiated by an ionization source. The irradiation time and intensity were suitably determined within the limit of the generation of aerosols from chemical reactions by the absorption of ionizing radiation. The bipolar small ions generated by the ionization source quickly collide with aerosols so that the charged fraction will approach to an equilibrium state. If the properties of aerosols (e,g. shape ect.) are the same, the charged fraction will only depend on the particle size. The ion mobility distribution of equilibrium state brought about by the irradieation was obtained with an mobility analyzer. Also the relation between particle size and charged fraction in the field of bipolar small ions was experimentally determined and compared with some theoretical data. Using the relation the particle size distribution was transferred from the ion mobility distribution. 


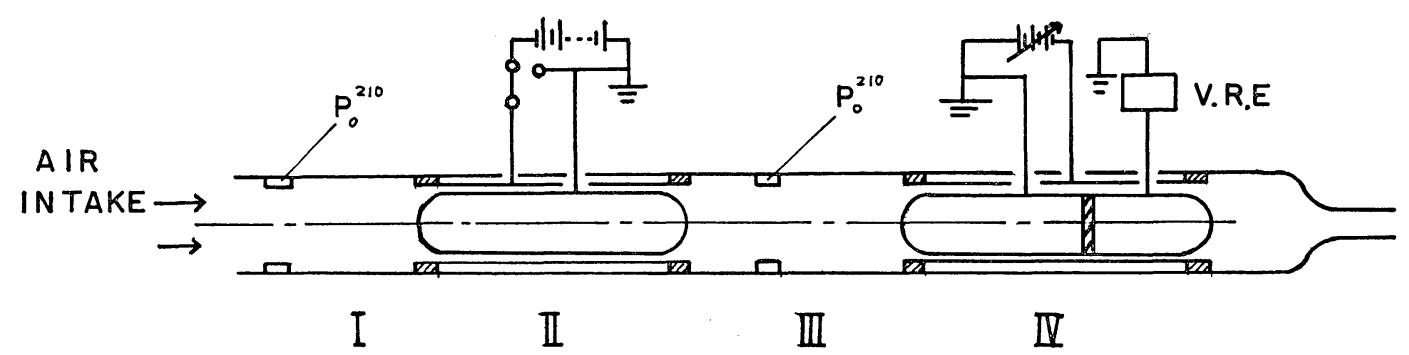

Fig. 1 The schematic diagram for the measurement of the charged fraction

\section{The measurement of the charged fraction}

a) The principle

The study of the charged fraction has been done theoretically by many researchers [Bricard (1949), (1962), Junge (1955), Keefe (1960), Fuchs (1963)], but experimental treatment has not been done except in a few reports (Nolan 1949). He measured independently the charged fraction and the radii of platinum particles produced by heating a wire.

We adopted the following method. The diagram for the measurement is shown in Fig. 1.

I: The first ionization chamber with $\mathrm{Po}^{210}$

The air was irradiated by four pieces of po $210(100 \mu \mathrm{Ci})$ sticked around the inside of the tube of about $10 \mathrm{~cm}$ in diameter. The strength of $\mathrm{Po}^{210}$ is sufficient to quickly produce charge equilibrium with the flow rate used.

II: Ion denuder

This can remove all the charged particles with mobility larger than $5 \times 10^{-9} \mathrm{~m}^{2} / \mathrm{V}$. sec.

III: The second ionization chamber

Here the uncharged particles which were not removed in II are brought to charge equilibrium.

IV: Ion mobility analyzer

The first inner electorde is not connected to the vibrating reed electrometer (V.R.E.) but can remove all the small ions which are not attached to aerosols.

In the range of $I$

$$
\mathrm{Zr}=\mathrm{Nr}+\mathrm{Nor}
$$

where $Z r$ is the concentration of aerosols with radius $r, N r$ is that of charged aerosols, and Nor is that of uncharged aerosols. In the range of III

$$
N o r=N^{\prime} r+N^{\prime} \text { or }
$$

where $N^{\prime} r$ is the concentration of aerosols charged by $\mathrm{Po}^{210}$ of III, and $N^{\prime}$ or is that of uncharged aerosols. Since the charged fraction depends on the particle size, the following equation is given:

$$
\frac{N r}{Z r}+\frac{N^{\prime} r}{N o r}=a_{r}
$$

where $a_{r}$ is the charged fraction of particle size $r$. Manipulation of equation (1) yields the relation

$$
a_{r}=\frac{N r-N^{\prime} r}{N r}
$$

When a high voltage is supplied to the ion denuder, $N r^{\prime}$ is obtained by the ion analyzer, and when not, $N r$ is obtained. Thus we can determine experimentally the value of $a_{r}$ from equation (2).

b) Ion mobility analyzer

For obtaining $a_{r}$ four ion-mobility distributions, i.e. positive and negative $N r$ and $N^{\prime} r$, must be measured. Therefore it is necessary to devise an ion analyzer which can measure the ion-mobility distribution in a short time. Fig. 2 shows the detailed diagram of the ion mobility analyzer of the multielectrode type which is schematically shown in the range of IV in Fig. 1.

The inner electrode $7.0 \mathrm{~cm}$ in external diameter is divided into nine sections, electrically insulated from each other by teflon cylinders. Each section, with the exception of first one, is connected to the V.R.E. by a wire leading through a brass tube lying inside the inner electrode. The first section is always earthed. The inner electrode is enclosed coaxially by another cylinder of brass, $152.5 \mathrm{~cm}$ in length and $8.0 \mathrm{~cm}$ in internal diameter, connected to dry 

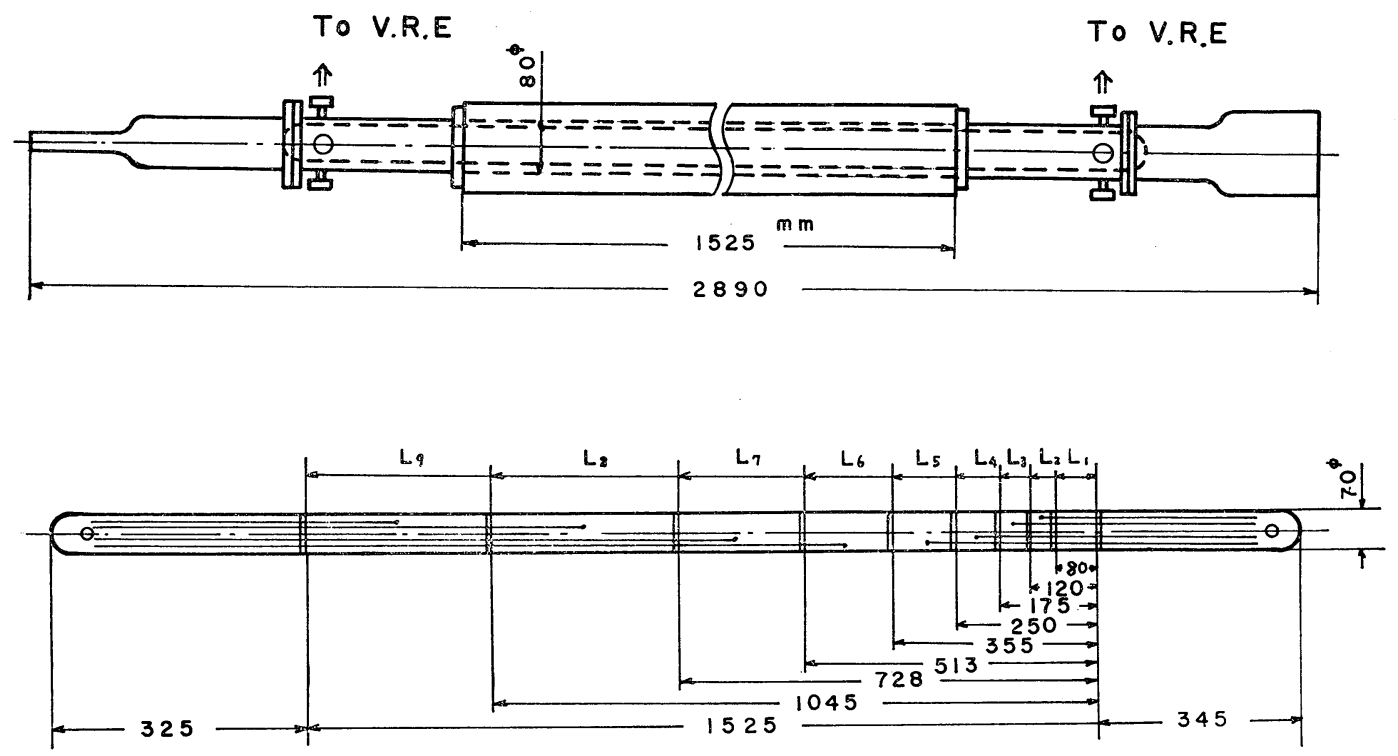

Fig. 2 The ion mobility analyzer of the multiple electrodes type

batteries. The air flow passes between these two cylinders. A third cylinder of $5.0 \mathrm{~cm}$ in diameter inside the inner electrode has the function to keep the central electrode in a horizontal position and to protect the wire from noise. A fourth cylinder of $14.0 \mathrm{~cm}$ in diameter encloses the three torementional cylinders in order to make the electrostatic shielding more efficient. From the ion currents obtained with the analyzer of the multielectrode type, the ion-mobility distribution was calculated by using the method which was developed by Nakatani (1972). The airflow between electrodes must be laminar. We confirmed this using smoke of visible size.

This analyzer has the following advantages: (1) Complete continuos data can be obtained. (2) As the analyzer does not require varying the supply voltage, this can cause a greater decrease of the troubles which would arise from varying the voltage. Accordingly the analyzer may be effective for quickly variable phenomena such as the measurement of the coagulation process of aerosols.

On the other hand, since the bulk of the analyzer becomes large, it is not convenient for observation in the field. Another disadvantage of our analyzer is connected with the characteristic of the V.R.E. and each divided electrode. If they have different characteristics, it is necessary to make the correction, To clarify the characteristics of the present analyzer, the following measure-

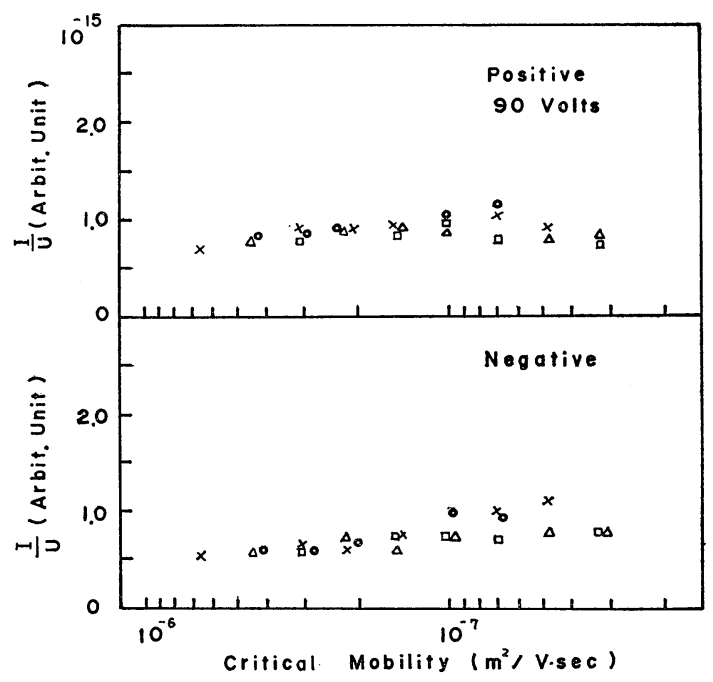

Fig. 3 (a) The characteristic curves of variabl airflow.

$$
\begin{aligned}
& \bigcirc 35.0 \mathrm{l} / \mathrm{min} . \triangle 16.5 \\
& \times \quad \square \quad 11.5
\end{aligned}
$$

ments were made. In Fig. 3(a) the characteristic curve of airflow (U)-current (I) is shown. Since the supplied voltage $(\mathrm{V})$ is kept to be constant, the critical mobility $(\mathrm{kc})$ of each electrode is proportional to $\mathrm{U} / \mathrm{L}$, where $\mathrm{L}$ is the distance of each electrode from the entrance of airflow. Each value of $U$ was taken so that $U / L$ is the same ratio for some different electrodes. For example, the critical mobility of the ninth 


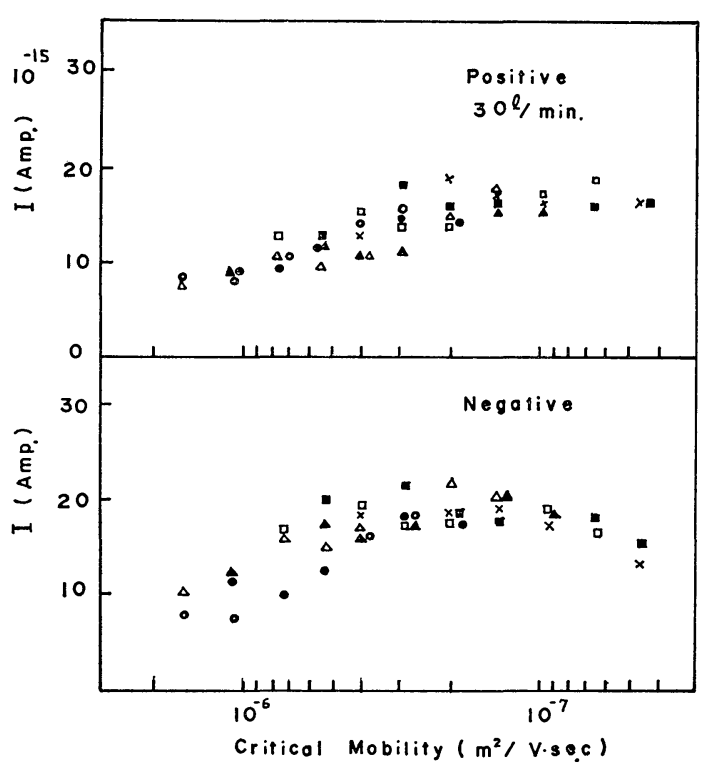

Fig. 3 (b) The characteristic curves of variable voltage

$\begin{array}{llll}\bigcirc & 19 \text { volts } & \square & 87 \\ \odot & 28 & \square & 127 \\ \triangle & 41 & \times & 180 \\ \triangle & 60 & & \end{array}$

I: The current collected to the electrode,

$L$ : The distance of electrode from the entrance of airflow, $V$ : The supplied voltage

electrode for airflow of $35 \mathrm{l} / \mathrm{min}$. is equivalent to that of the eighth for airflow of $24 \mathrm{l} / \mathrm{min}$. If we perform corrections of the airflow upon the currents of both electrodes, both $\mathrm{I} / \mathrm{U}$ will be equal. Fig. 3 (b) represents the characteristic curves of voltage-current when the critical mobility is varied by the supplied voltage instead of the airflow. If each electrode and the V.R.E. have different characteristics, systematic errors will arise on the experimental points. From the figure no obvious difference is found.

By sending ion free air, the background current of the analyzer was measured. Since the current showed remarkable increase with high voltage, the voltage was kept below $180 \mathrm{~V}$.

\section{c) Experimental results}

For determining $a_{r}$ the measurements were carried out by introducing the urban air into the analyzer. The time required for one run was about $30 \mathrm{~min}$. The mean values of experimental points and standard deviation are shown in

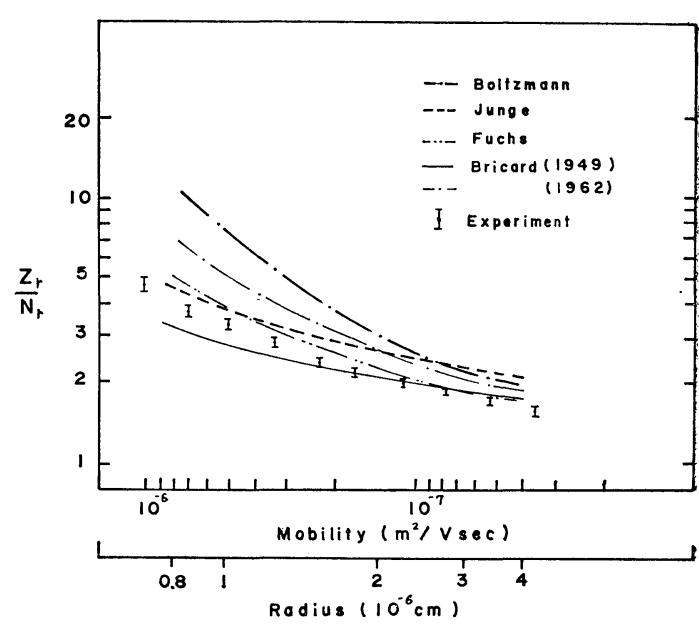

Fig. 4 The relation between $Z r / N r$ and the particle radius

Fig. 4. The charged fraction was determined for radii less than $4 \times 10^{-6} \mathrm{~cm}$, since for those above this value the fraction of doubly-charged particles becomes significant [Fuchs (1963)]. The charged fraction was indicated with $\mathrm{Zr} / \mathrm{Nr}$, which is the reciprocal of the ratio of the charged particles to the total concentration for each radius, for comparision with the values by other researchers. The standard deviation of measurement was small because measurement was carried out for 30 times. The theoretical values obtained by several authors in a case of bipolar ions were plotted in the same figure.

The Bricard (1949) and Fuchs curves seem to approximately fit the present experimental points, but the Boltzman law and Bricard (1962) curve seem to be too high in the range of small size. The experimental values by Nolan (1949) indicated that Boltzmann law appears to be satisfactory in its application to large particles but difficulties arise when it is applied to particles less than $1 \times 10^{-6} \mathrm{~cm}$ in radius.

\section{Measurements of the size distribution of natural aerosols}

a) Instruments and method

The ion analyzer of double electrode type, which has been developed by Misaki (1960), was used for measuring ion mobility distribution of natural aerosols. The analyzer consisted of outer electrode of inner diameter $5.7 \mathrm{~cm}$ and $58.0 \mathrm{~cm}$ long, and inner electrode of outer diameter 
$5.1 \mathrm{~cm}$. Inner electrode was divided into two parts i.e. first electrode of $42.5 \mathrm{~cm}$ and second electrode of $15.0 \mathrm{~cm}$. Only the currents which were collected to the second electrode were measured with the V.R.E. The flow rate through both electrodes was $7 \mathrm{l} / \mathrm{min}$. and supplied valtages between electrodes was varied from 10 to 201 volts with voltage interval such as is logarithmically equal. Before entering the analyzer the air was irradiated by $\mathrm{Po}^{210}$. By using the formula of Fuchs (1962), electrical mobility was transformed to particle radius. On the base of our experimental values on the charged fraction, ionsize distributions were transformed to particle size distribution. The correction on multiple charged particles was not carried out.

b) An example of diurnal variation of particle size distribution

The place of observation is near streets of heavy traffic disturbances and industrial centers; that is, in a laboratory, 5 meters above the ground level, of the Department of Physics, Science University of Tokyo.

Fig. 5 is a typical example of size distribution in fine weather. The concentration of aerosols of each size range decreases gradually as night goes on and just before dawn becomes approximately one fifth of that in the evening. In the early morning it shows a tendency to increase.

Tok y o

July $\quad$ II 12 1969

$17: 50$

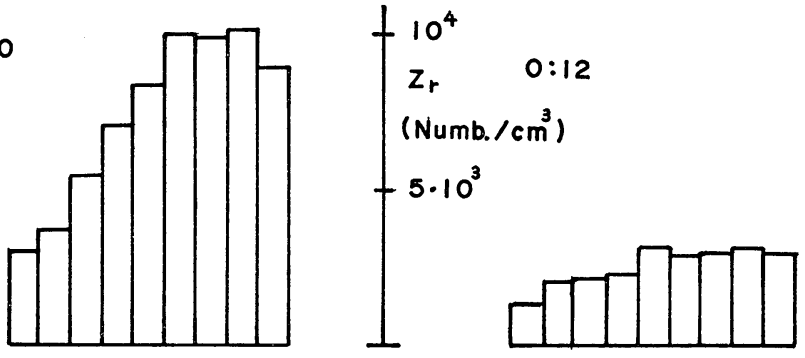

$20: 14$

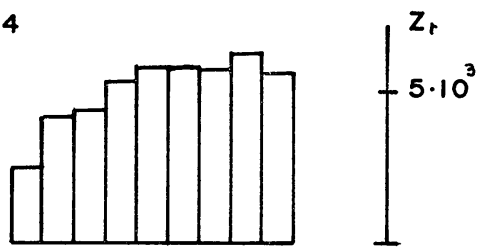

$3: 26$

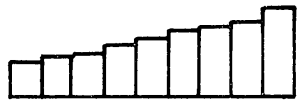

$22: 38$
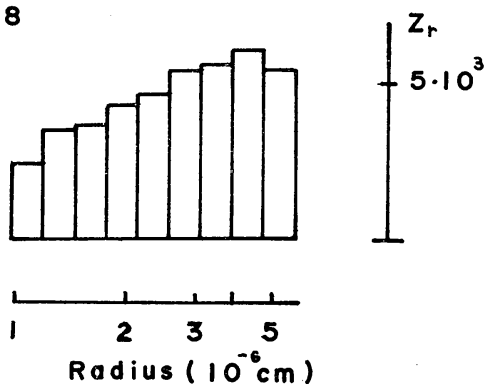

$5: 50$

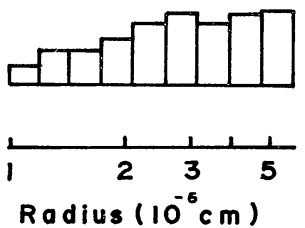

Fig. 5 An example of the diurnal variation of size distribution of aerosols in the atmosphere 
These variations may agree with that of human activity. Not only the concentration but also the size distribution is seen to vary with the lapse of time. The paek in size distribution exists near the mobility of $4 \times 10^{-8} \mathrm{~m}^{2} / \mathrm{V} \cdot \mathrm{sec}$ (about $4 \times 10^{-6} \mathrm{~cm}$ in radius) at about $18 \mathrm{~h}$. but it mostly disappears with the lapse of time. It shifts toward the lower mobility region. Such a change may be naturally influenced by processes of generation and disappearance of particles, but a large amount of data would be required for a detailed discussion of it.

There have been few reports in which size distribution in our range is obtained continuously, while there have been many studies on total concentration of aerosols which can easily be measured with the Pollak counter (1959). Experiment with the Pollak counter is easy to do, but it is 'rather difficult to interpret the data. Although our method is not accurate enough for practical use, it may be useful in the study of the characteristics of aerosols.

\section{Concluding remarks and discussion}

In this paper is studied the method of measuring the size distribution of aerosols in the atmosphere. The ion mobility distribution brought into charge equilibrium with $\mathrm{Po}^{210}$ was measured by the ion mobility analyzer and transformed into aerosol size distribution. Applying it to the measurement of aerosols in the atmosphere, it is seen that the variation of the size distribution is reasonable. Comparision was done between experimenta! and theoretical values of the relation of the particle size to the charged fraction. Our experimental values differed from Boltzmann and Bricard (1962) theories and experimental values by Nolan (1949) and with decreasing the size the differences increased. On the other hand our values were rather close to the Bricard (1949) and Fuchs theories. Many problems are yet to be solved with regard to transference from ion mobility distribution to aerosol size distribution. For example, it is reported that Megaw (1968) axperimentally determined the relation between electrical mobility and particle size in the size range less than $10^{-5} \mathrm{~cm}$ in radius, and that his results did not agree with the theoretical values (Fuchs 1962). Also, with the enlargement of the particle size the multiply charged particle can not be ignored. To oive the above problems and to know the accuracy of our experimental values are very difficult. Therefore, the size distribution obtained by our method must be compared with the particle size distribution obtained with other sizing method, or calibrated by using monodisperse aerosols of known size. They will be our task in future.

\section{References}

Bricard, J., 1949: L'equilique ionique de la basse atmosphere. J. of Geophys. Res. 54, 39-52. 1962: La fixation des petits ions atmospheriques sur les aerosols ultra-fins. Geof pura e appl. 51, 237-242.

Flanagan, V.P.V., T.C. O'Connor, 1961: Ionization equilibrium in aerosols. Geofis. pura e appl. 50, $148-154$

Flesch. J.P., 1969: Calibration studies of a new submicron aerosol size classifier. J. of Colloid and Interface Science 29, 502-509.

Fuchs, N.A., 1962: Resistance of a gaseous medium to the motion of spherical particles of a size comparable to the mean free path of the gas molecules. Trans. Farad. Soc. 58, 1949-1952.

ditribution 1963: On the stationary charge ionic atmosphere. Geofis. pura e appl. 52, 185193.

Junge, C., 1955: The size distribution and aging of natural aerosols as determined from electrical and optical data. J. Meteor. 19, 13-26.

Keefe, D. P.J. Nolan, and T.A. Rich. 1960: Charge equilibrium in aerosols according to the Boltzmann law. Proc. R.I.A. 60, Sect A. 27-45.

Megaw, W.J. A.C, Wells. 1968: Electrical mobility of sub-micron particles. Nature. 219, 259-261.

Misaki, M. 1960: Studes on the atmospheric ion spectrum. Pap. Meteor. Geophys. Tokyo 12, 247-261.

Nakatani, S., 1972: Improved apparatus for obtaining ionic mobility distributions of radioactive aerosols. J. Meteor. Soc. Japan. 50, 151-158.

Nolan, P.J., E.L Kennan. 1949: Condensation nuclei from hot platinium; size, coagulation coefficient and charge distribution. Proc. R.I.A. 52, 171-190.

Pollak, L.W. A,L, Metnieks 1959: New calibration of rhotoelectric nucleus counters. Geofis. pura $e$ appl. 43, 285-301.

Sekikawa, T. H, Kojima. 1969: Charged fraction and charged equilibrium on the submicron aerosol particles in the atmosphere. J. Meteor. Soc. Japan. 27, 329-334.

Whitby, K,T,. and W, W, Clark. 1966: Electrical aerosol particle counting and size distribution measuring system for the $0.015 \mu$ to $1 \mu$ size range. Tellus. 18, 573-586. 


\title{
大気中のエアロソルのサイズ分布測定におけるーつの試み
}

\author{
児島紘・関 川 俊 男 \\ 東京理科大学理学部
}

比較的測定が困難とされている半径 $5 \times 10^{-7} \sim 5 \times 10^{-6} \mathrm{~cm}$ の大気中のエアロゾル粒子のサイズ分布測定について一 つの試みがなされた.

イオンアナライザーにより $\mathrm{Po}^{210}$ (約 $100 \mu \mathrm{Ci}$ ) で照射されたイオン平衡になった空気のイオン易動度分布が測定さ れた. 荷電率（ある半径の粒子総数と電荷を持つ粒子数の比）をイオンデニューダーとイオンアナライダーを直列に つなげて使用する事により実験的に求めた。矢の結果は Bricard (1949) や Fuchs (1963) の理論值に近かった. 実 験的に求めた荷電率をもとにイオン易動度分布から粒子のサイズ分布に外插した. 